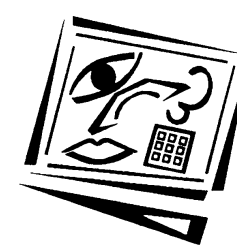

\title{
A networked learning community approach to sustain teacher ICT professional development
}

\author{
Glenice Watson and Sarah Prestridge \\ Griffith University
}

\begin{abstract}
This paper explores the process of collaboratively creating a networked learning community of practising teachers to support information and communication technology (ICT) professional development. The paper reports on one aspect of a continuing ARC funded Linkage project that is concerned with models of teacher ICT professional development that result in multiliterate classroom outcomes. The industry partner for the project is the Suncoast Cyberschools, a group of regional schools for whom being a 'networked learning community' is fundamental to their purpose. Data reported in this paper were gathered using archived posts to a threaded discussion forum and analysed qualitatively for evidence of community development, and quantitatively through a process of categorising posts to reflect levels of discussion (Järvelä \& Häkkinen, 2002). The research provides a number of indicators that support a claim for the existence of community and some practical stages that are essential to the formation of an online learning community. The findings of this research inform both ICT professional development for practising teachers and the functioning of online learning communities.
\end{abstract}

\section{Introduction}

While teacher professional development is well understood as an inherent component of educational reform, what constitutes effective models of continuing professional development is highly contested (Becher, 1999; Knight, 2002; Shulman, 1987). Schlager and Schank (1997, p.1) conclude from their review of education reform research that new models of teacher professional development are needed to establish and support communities of teachers engaged in school reform'. Lieberman (2000, p.222) observes that having a professional community differentiated those teachers who worked together for systematic reform, compared with those who tried new ideas in fragmented ways. 
Communication technologies have been promoted as a platform that provides opportunities for learning communities, enabling many to many communication that is not place or time dependent (Rovai, 2002; King, 2002). However as Zhao and Rop (2001, p.5) illustrate 'the claims and research in this area raises far more questions than it answers'. Literature relating to online learning communities frequently focuses on higher education (Caverly \& MacDonald, 2002; Lieblein, 2001; Pearson, 1999), or distance education (Clark, 2001; Rovai, 2002), and explores characteristics that help maintain and facilitate discussion and learning in these fields of education. However these characteristics do not necessarily relate to an online learning community of teachers, because there is no specific course structure to support and provide a purpose for the community.

\section{Background}

This paper reports on one aspect of a continuing research project that has as its goal the development of sustainable and transformative models of teacher information and communication technology (ICT) professional development that empower multiliterate student outcomes. The project is supported by funding from the Australian Research Council, an industry partner, and Griffith University. The industry partner, the Suncoast Cyberschools, is a group of regional schools trialing an educational reform project targeted at curriculum, pedagogy and assessment (Education Queensland, 2000). This project enlists ICT as a major platform, both to underwrite the need for reform and as an aid to pedagogy (Queensland Government, 2002). It highlights the need for teacher's ICT professional development on the basis that teachers need 'to understand how ICTs promote higher order thinking and deepen understanding' and that 'using ICTs effectively demands new teaching strategies and different approaches to assessment' (Department of Education, 2002, p.5).

To date, the research project has involved the establishment of baseline data through survey, interview and classroom observations within the industry partner schools, who are also the research participants for the project. This baseline data included understandings and practices with respect to ICT, multiliteracies, and models of professional development (Prestridge \& Watson, 2002). A series of face to face meetings, involving researchers with principals and interested staff of the participant schools, have been held to design the process and nature of the required/desired professional development. An action research model is being implemented with the second stage of the project to enhance ownership and improve sustainability. The online community described below has been developed to support this phase of the research. All names used in the data reported in this paper have been replaced with pseudonyms. 


\section{An online learning community}

The promotional material for the Suncoast Cyberschools identify them as a 'networked learning community' dedicated to acting as a catalyst for sharing, building relationships and development within school communities. The stated purpose of the Suncoast Cyberschools Project is to establish an education model for communities of the future. This is to be approached in the following three ways: through the exploration of a curriculum that is embedded in authentic pedagogy and is aligned to a notion of community; the concept of a learning community; and enhancing teacher professionalism. The Suncoast Cyberschools have a formal memorandum of understanding with Griffith University for the purpose of alliance to promote: the concept of life long learning; a curriculum embedded in authentic pedagogy which aligns with community needs; and the professionalism of teaching. Under this memorandum, the Cyberschools are committed to providing 'an opportunity to take part in programs for staff exchange, student support and research' while Griffith University has agreed to 'audit courses, do research and take part in teaching programs'.

Zhao and Rop (2001, p.11) note that while many researchers claim benefits from online learning communities, they rarely problematise the issues of community itself. These authors identify the following factors as problematic for success for teacher online learning networks: technology, motivation, project time frames, time to participate, and project goals (pp12-13). As schools within the state education system, the Suncoast Cyberschools have access to Internet connections and service provision. A recent innovation of their education system has been the provision of a web site that enables the establishment of communication forums through the Blackboard infrastructure. These facilities have provided a technical and professional climate that is supportive of the establishment of an online learning community, but this does not mean that effectiveness of that community is necessarily unproblematic.

DiMauro and Jacobs (1995, pp128-9) identify the following social factors as playing a critical role in cooperative community building: purposeful design motivated by a clear pedagogical perspective that reflects users' needs and interests; involvement of a leadership group; facilitating a common understanding between users; and negotiation of common understandings. Schlager, Fusco and Schank (1998/99) catalogue the following 'cornerstones' for an online community of education professionals: supports the same ebb and flow of communication and information sharing that face to face work teams engage in over time; requires the participation of several organisations representing a variety of 
approaches and perspectives; and as a life long process that occurs in the context of daily practice.

In the discussion section that follows, the participants' posts to the online forum are discursively analysed for 'motifs' (Gee, 1999, p.137), as suggested by DiMauro and Jacobs' 'social factors' and Schlager, Fusco and Schank's 'cornerstones' above, that could be seen as indicative of community building in an online environment. A further quantitative analysis, as demonstrated by Järvelä and Häkkinen (2002, p.11), is employed to gauge the extent to which this online community might be considered as an online 'learning' community.

\section{Discussion}

As noted earlier the participants in this research project are a group of regional schools that have some geographical separation from each other and considerable separation from the researchers. However as they are well supported by ICT infrastructure, and ICT professional development is fundamental to the research project, the researchers sought to engage the participants with electronic communication. An asynchronous threaded discussion structure was seen as the best way to stimulate community within the constraints of the teaching work environment. This was implemented via the forum communication tool in a Blackboard environment. From a review of the literature, Zhao and Rop (2001, p.8) suggest that the goals of 'electronic teacher networks' can be classified into three groups: sharing information, fostering professional development, and creating communities. The project forum was conceived as having each of these goals.

The forum was introduced to the participants in a computer laboratory at the researchers' university during a day designed to introduce the action research phase of the project. Many participants had not used a forum before, so they were given time to post messages to the forum and respond to each other, even though they were located in the same physical space. Some continued to post on the topics afterwards. In total this forum (Forum 1) generated 48 posts. In this initial experience there is strong evidence of deferral to the 'expertise' of the researcher (Sarah) in what is more like a 'many to one' relationship rather than the many to many relationship that the forum structure facilitates. For example Sarah asked questions to stimulate discussion such as what principles underlie effective ICT integration? This elicited a number of practical responses such as:

[Charles] An expectation that technology is used across curriculum, to meet individual student needs, and in daily administrative life of school would develop gteacher [teacher] experience and eventually confidence to use.

Availability of computers and tome [time] for teachers to access essential. 
Whilst teachers have a professional responsibility to develop their skills, inservicing to "certain standard" or expectation is necessary to encourage confidence and competence in using technology.

While most of the posts were within the 'thread' generated by Sarah's question on the principles underlying ICT integration there were two distinct 'sub-threads' that generated discussion between the participants, that is a 'many to many' relationship, as distinct from a 'many to one' response to Sarah. The first was around the idea of lab based or classroom based computers, a topic that has been long debated by the educational ICT community. The second related to teacher professional development as exampled by the following posts:

[Edward] Accepting staff where they are at to a degree. But there comes a time when teachers need to accept responsibility for their own skill development. If we keep offering a 'crutch' for them (spoonfeed them) then we are not allowing them to develop professionally, nor to take ultimate responsibility.

[Leslie] What is own time? After 3pm. But lots of people plan after 3pm. Most people have computer and internet at home. But must not overload teachers. So must be win-win. ICT should be reducing workload if it is working properly. Professional dialog, more info etc, clarifying requirements.

This latter 'sub-thread' demonstrated the value of controversy in generating postings. To what extent this builds community or silences is not clear. Dillenbourg (1999, p.13) suggests that collaborative learning environments must not only provide space for negotiation but also space for misunderstanding. Mitchell and Mayer (2002, p.17) advise that conceiving of community as a process of negotiating meaning enables the possibility of taking conflict and different values into account in our understanding of community.

A further thread generated by Sarah asked about identification of multiliterate student outcomes but that did not generate much response except as follows:

[Hillary] *risk taking *open ended situations * critical reflection

The different level of response to this thread might demonstrate the importance of one of DiMauro and Jacobs' (1995) critical social factors for community, that of shared understandings with respect to the topic. Baseline research had earlier revealed that the participants had a limited understanding of the concept of multiliteracies (Watson \& Prestridge, 2002). Multiliteracies are defined in the curriculum reform documents with which the participants are engaged as: 'new kinds of literacies ... different kinds of intelligences and dispositions, knowledges and skills to 
engage with blends of oral, print, visual and multimediated communications simultaneously' (Education Queensland, 2000, p.10). This definition, while exciting in its possibilities, is complicated in its interpretation, so imperfect understanding at this early stage of the reform process is not surprising. The limited response to this topic could also possibly reflect the immature stage of the community building, in that the participants felt unsafe contributing posts on a topic about which they were unsure, in a communication medium that 'published' and stored their thinking.

While there was evidence of shared professional understanding in the postings there was no sense of social interaction that might be expected if community was being engendered. Most of the postings used the third person except for one brief posting that said Hear hear, I think we've got it right! and one that used 'we' as a collective pronoun for teachers as a group. However there was some evidence of a willingness to be more personal in reflections on the day that were posted later such as:

[Hazel] I arrived feeling a bit irritated after our eventful trip down to

Brisbane. After that things got much better. I liked the first reading which was succinct and useful, but found the second reading too verbose. I

thought what the second reading was saying was fairly trivial for so many

words. Sarah's powerpoint about multiliteracies put lots of things into

context for me.

The personalised aspects of this posting was probably a response to the nature of Sarah's stimulus statement that asked them to comment on what you got out of the day thus inviting personal response. It also could reflect preparedness on the part of the respondents to be more open to their colleagues, as a result of the community building that occurred from having shared the day together in the same physical environment.

After the initial meetings of participants and researchers, as described above, a series of face to face meetings were held to make decisions on the future shape of the project. During this process, it was collaboratively decided to make inquiry projects form the foundation of the ICT professional development to achieve multiliterate classroom outcomes. In each of the eight schools involved with the project, a teacher 'candidate' volunteered to investigate their pedagogical practices in regard to ICT and multiliterate student outcomes. In turn, these 'candidates' are supported by a 'project team member' who has the dual role of supporting the candidate and working with the researcher in designing, monitoring and evaluating this professional development model.

During the design phase, it was decided that participation in the forum (Forum 2) would be mandatory. It was further decided that during the 
implementation phases, each school would be responsible for leading discussion on the forum over a two week period. The project team decided that the researcher was to go first to demonstrate how to lead a discussion. This is in keeping with Manning and Payne's (1993, p.364) observation that 'the mechanism for growth in the zone [Vygotsky's concept of zone of proximal development] is the actual verbal interaction with a more experienced member of society. However, to improve the sustainability of the community, this leadership must, over time, evolve to the community members themselves.

The participants were provided with documentation that outlined the project and advised on how to lead a discussion, including responding to postings, topics or ideas to focus on, and encouraging collaborative critical discourse. The researcher (Sarah) opened the forum as follows:

[Sarah] For the next two weeks we will be supporting one another through the formation of your action plans. These should be emailed to me by the 11th April. You will need to download the form from the Documents section. If you have any questions, thoughts or problems with documenting your existing situation and action plan reply to this message. I encourage everyone to provide support and encouragement.

This post provided an activity as purpose for initial engagement with the forum and encouraged collaboration. For many of the participants this was their first experience of contributing to the forum, outside of the technical support provided by the researchers. Not surprisingly some of the earliest posts were of a technical 'trialing' nature to see if it was working such as:

[Beverley] Hi all. Just a quick test to make sure I am accessing correctly.

Charles has spent some time preparing and planning our inquiry project.

Back soon with real discussion.

By its address to 'all', this post suggests some development of community. It also acknowledges the potential of the forum for 'real' discussion. The form of address such as 'Hi everyone', 'G'day to you all' of these early posts suggests a much stronger sense of community than existed at the time of the first forum discussed earlier. The form of address also points to ambiguity with the genre of the forum as a mean of communication, between the conversational forms of ' $\mathrm{hi}$ ' and ' $\mathrm{g}$ 'day' and the written form of 'Dear' as would be used in a written letter genre. As the forum progressed the postings tended not to have any form of address.

Following the opening posts that could be seen as 'getting comfortable' with the communication medium, the researcher used her 'expert' standing to influence the direction of the discussion on to inquiry projects by replying: 
[Sarah] Thanks Beverley. Charles has a very hot topic. There has been much discussion about how to use the internet effectively and I think that a Multiliteracy focus is what is required. The internet is a dynamic medium where students use different skills and literacies to make meaning. Looking at it through a multiliterate lens will be really interesting for all of us. Is Charles planning to use the internet in next terms unit of work. If so what are you planning to do to analyse your pedagogy and learning activities?

From the use of individuals' names in this post, it could have been expected that these people would be the respondents to it. However a response came not from Beverley or Charles, but from another participant to support this development of critical discourse:

[Janelle] Questions to clarify and unpack question: What literacies and skills are already being explicitely [explicitly] taught and learnt in present units of work? (Rich Tasks). What literacies and reportoires [repertoires] of practice are needed to use internet effectively. How do you incorporate these needs into your planning and pedagogy?

Sarah tried to continue this support by offering further questions for thought:

[Sarah] Great questions Janelle...would stimulate much thought. I'll add some: Why use the Internet? In what way are you using the Internet? Is this the only way? Is this appropriate to the learning outcomes you want achieved? Are their more powerful ways that children can get information than by surfing the Net? Could discussions with real people in the appropriate fields be more realistic and educational?....any experiences others want to share re internet use..

This was the third day of this forum and it can be seen that already a professional cohesive critical discourse was developing. However a technical problem arose which quickly changed the 'thread of discussion' towards more basic administration duties. What had occurred was a problem downloading the planning document:

[Trevor] Hi Sarah. Jeremy and I have had a look through the documents section and have a few questions for you. 1. The planning document. We opened the planning document. We don't know how to work on it and then save it. We tried 'Word Edit' and it didn't work. All we got was a message 'Please Wait'. We are still waiting

2. As we have to send you an electronic copy we would like to work on it, edit it, alter it and so on so we will have to know how to go about this.3. Is this the correct spot for these queries or should we email you direct?

This post, while ostensibly making a simple technical query, also explores the genre of the forum as a many to many communication tool with the realisation in question three that the one to one nature of the query might not be suitable for the genre. However this was a shared problem and a 
fellow participant affirmed Trevor and provided support to the query by addressing Trevor directly:

[Hillary] Dear Trevor ,...... we had the same problem with trying to work on it. We are unable to download it also. Any ideas?

If Hillary chose she could have remained silent and waited for Sarah's reply, rather than expose what could have been her own technical incompetence. This would suggest the development of a level of trust in the community and is an example of the importance of feedback in the development of that community as noted by Mäkitalo, Häkkinen, Leinonen and Järvelä (2002). These authors propose that agreement/ disagreement, personal, notifying, supporting, comparing, and paraphrasing are all important forms of feedback in communities. The development of community, and perhaps a growing technical confidence, can also be seen in the more relaxed approach evident in the following post:

[Hillary] Dear Sarah, and hi to you all. Hazel and I are very high achievers and are sure we will manage to complete our project planning sheet by the 11 April as you requested. We promise not to party, shop, or play with the grandkids for the next seven months. Hazel has even deferred her open heart surgery and face lift until next year so that she can concentrate on her inquiry project

Yours in professional learning development Hazel and Hillary

DiMauro and Jacobs (1995) list 'involvement of a leadership group' among the critical social factors for community building but this leadership can be problematic. For example in trying to encourage greater reflection, Sarah asked:

[Sarah] Any thoughts or issues associated with monitoring your actions in the first cycle? Has anyone thought about data collection techniques?

The first response to this post was by Trevor who said:

[Trevor] I thought that you might have a checklist of tasks/skills that need to be completed and as this is done you check them off. Regards Trevor

This post is problematic for Sarah because it is not in keeping with her goals for the project, but Sarah is concerned not to alienate the participant, so she frames her response in the form of questions, and tries to remove herself from her 'expert' role:

[Sarah] Has anyone any experience with skill checklists? Do they work? It depends on what outcomes you want to achieve and what focus you put on the technology? Comments. 
Mitchell and Mayer (2002, p.18) note that in their research some participants read their moderation comments as regulatory and serving to 'stifle' or 'silence' discussion. Sarah was fortunate in that the thread was picked up with a response by Lucinda, that was more in keeping with her goals for the project, and provided opportunity for continuing discussion:

[Lucinda] Yes they can work on simple skills such as turning the computer on but they dont always tell you what the children understand. For my self I am going to ask the children to start a learning journal for this term whereby they reflect on their learning and through the journal tell me in words or drawings about what they have learnt and understood as we investigate multi modal presentations. I think (in regards to earlier thoughts mentioned above) that we all at one time or another get locked into thinking that mulitliteracies, particularly when mentioned in the same sentence as ICT is the internet and computers and the like. Sometimes we are so keen to embrace the new that we forget the old.

This section has provided a preliminary qualitative analysis of the posts of the forums suggesting some development of community. However as Dillenbourg (1999) notes, a 'learning community' requires analysis both of the collaborations between the community and the learning that is taking place. This paper reports on a project that is still in its early stages, so there is little expectation of evidence of significant learning. However, a preliminary quantitative analysis on the type of posts suggests some development of cognitive demand. Järvelä and Häkkinen (2002, p.11) demonstrate how categorising posts according to a continuum from 'comment' through 'suggestion', 'experience', and 'newpoint/question' to 'theory' support the identification of levels of discussion. Table 1 provides a percentage comparison of the posts to the two forums using this classification system. It can be seen that the lower 'comment' and 'suggestion' levels of discussion were more prevalent in the first forum compared with the second, while the higher levels of 'experience', 'newpoint/question' and 'theory' were more common in the second forum compared with the first.

Table 1: A comparison of level of discussion between Forums 1 and 2

\begin{tabular}{|l|c|c|}
\hline Level of discussion & $\begin{array}{c}\text { Forum } 1 \\
\% \text { of posts }\end{array}$ & $\begin{array}{c}\text { Forum } 2 \\
\% \text { of posts }\end{array}$ \\
\hline Comment & 48 & 30 \\
\hline Suggestion & 23 & 8 \\
\hline Experience & 16 & 42 \\
\hline New point/question & 26 & 38 \\
\hline Theory & 2 & 8 \\
\hline
\end{tabular}




\section{Conclusion}

This paper explored the development of an online learning community within a continuing professional development model. It concurs with Zhao and Rop (2001), that 'community' cannot just be assumed, but requires problematising, if the online community is to be an effective tool for professional development. It also acknowledges Dillenbourg's (1999) requirement that an online learning community must demonstrate both community and learning.

A number of the theoretical concepts regarding community, as identified by DiMauro and Jacobs (1995) and Schlager, Fusco and Schank (1998/99) and discussed earlier, are supported by the data of the paper. It would appear that the possibility of both face to face and online communication has facilitated the development of community. The shared goals and understandings of the group as teachers within a regional area, and the existing policy links supportive of functioning as a learning community, also could be viewed as encouraging community. The participation of multiple organisations represent a variety of approaches and perspectives, and the involvement of a leadership group are also evident.

However it should be noted that the development of community is not a smooth curve. At various times impediments in that development appeared such as the technical problem and the post that was at odds with the researcher's goal for the project. Figure 1 suggests how this development might be represented graphically. What is not clear is the extent to which the impediments move the developmental curve to a lower or higher level (as represented by the dotted lines in Figure 1). It would seem however that such 'impediments' should be expected in any development of an online learning community, and an important leadership role would involve determining if intervention was required, and what that intervention might comprise.

Within the online aspect of the learning community the data also reveals a number of practical factors. The provision of a structured environment in which to explore the forum tool provided an impetus to get involved, but the more reflective posts were generated outside of this environment. The initial involvement of the researcher was essential to the early stages of the online community, to generate direction and respond to technical problems. The role of the researcher within the online community is problematic and can just as easily serve to silence as to stimulate. It should not be assumed that the development of the learning potential of the online community will be a continuous curve, as from time to time technical difficulties or inappropriate comments by members can serve to 
distract from the community goals. Controversy and humour, the impersonal and the personal all seem to play valuable roles in the construct of online community, as they do in other enactments of community.

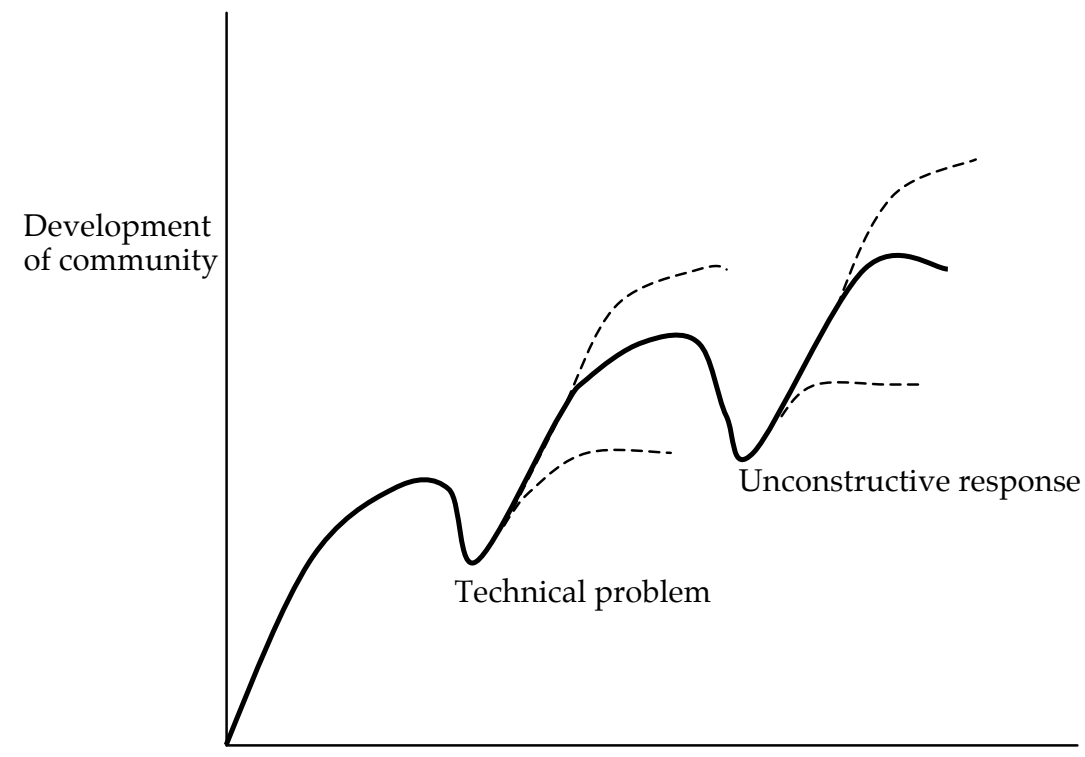

Time

Figure 1: Possible graphical representation of the development of a learning community

This paper reported on one aspect of a continuing research project. It has explored the initial stages of community development as evidenced by posts to threaded discussion forums. In the next stage of this research, the progressive posts to the online forums will be analysed for evidence of cognitive development in the teacher participants, and the interrelationship of that development with formation of community and the online tool.

\section{Acknowledgment}

This research is supported by the Australian Research Council, the Suncoast Cyberschools and Griffith University. The contribution of the principals and teachers in the Suncoast Cyberschools is invaluable to this project and is much appreciated by the research team. 


\section{References}

Becher, T. (1999). Professional Practices: Commitment and capability in a changing environment. New Brunswick, NJ: Transaction Publishers.

Caverly, D. \& MacDonald, L. (2002). Techtalk: Online learning communities. Journal of Developmental Education, 25(3), 36-40.

Clark, J. (2001). Stimulating collaboration and discussion in online learning environments. The Internet and Higher Education, 4(2), 119-124.

Department of Education (2002). ICTs for Learning. Brisbane: Queensland Government, Education Queensland.

Di Mauro, V. \& Jacobs, G. (1995). Collaborative electronic network building. Journal of Computers in Mathematics and Science, 14, 119-131.

Dillenbourg, P. (1999). Introduction: What do you mean by "collaborative learning"? In P. Dillenbourg (Ed), Collaboative learning: Cognitive and computational approaches (pp.1-19). Amsterdam: Pergamon.

Education Queensland (2000). New Basics Project Technical Paper. Brisbane: Queensland Government, Education Queensland.

Gee, P. (1999). An Introduction to Discourse Analysis: Theory and method. London: Routledge.

Järvelä, S. \& Häkkinen, P. (2002). Web-based cases in teaching and learning - The quality of discussions and a stage of perspective taking in asynchronous communication. Interactive Learning Environments, 10(1), 1-22.

King, K. (2002). Identifying success in online teacher education and professional development. The Internet and Higher Education, 5(3), 231-246.

Knight, P. (2002). A systemic approach to professional development: learning as practice. Teaching and Teacher Education, 18, 229-241.

Lieberman, A. (2000). Networks as learning communities: Shaping the future of teacher development. Journal of Teacher Education, 51(3), 221-227.

Lieblein, E. (2001). Critical factors for successful delivery of online programs. The Internet and Higher Education, 3(3), 161-174.

Mäkitalo,K., Häkkinen, P., Leinonen, P., \& Järvelä, S. (2002). Mechanisms of common ground in case-based web discussions in teacher education. The Internet and Higher Education, 5(3), 247-265.

Manning, B. \& Payne, B. (1993). A Vygotskian-based theory of teacher cognition: Toward the acquisition of mental reflection and self-regulation. Teaching and Teacher Education, 9(4), 361-371.

Mitchell, J. \& Mayer, D. (2002). Mediating and regulating teacher education discourse: Shifting goal posts in an electronic learning community. Paper presented at Australian Association for Research in Education Conference, Brisbane, December. 
Pearson, J. (1999). Electronic networking in initial teacher education: Is a virtual faculty of education possible? Computers and Education, 32(3), 221-38.

Prestridge, S. \& Watson, G. (2002). To construct or to skill? Effective Information and Communication Technology professional development within school reform. Paper presented at the Australian Association for Research in Education Conference, Brisbane, December. [verified 30 Jul 2003] http: / / www.aare.edu.au/02pap/ wat02393.htm

Queensland Government (2002). Queensland the Smart State: Education and Training Reforms for the Future. Brisbane: Department of the Premier and Cabinet.

Rovai, A. (2002). Sense of community, perceived cognitive learning and persistence in asynchronous learning networks. The Internet and Higher Education, 5(4), 319332.

Schlager, M. \& Schank, P. (1997). Tapped in: A new on-line teacher community concept of the next generation of internet technology. Paper presented at the Second International Conference on Computer Support for Collaborative Learning, Toronto, December.

Schlager, M., Fusco, J., \& Schank, P. (1998/99). Cornerstones for an on-line community of education professionals. IEEE Technology and Society Magazine, $17(4), 15-21,40$.

Shulman, L. (1987). Knowledge and Teaching: Foundations of the New Reform. Harvard Educational Review, 57(1), 1-22.

Watson, G. \& Prestridge, S. (2002). The interaction between ICTs and Multiliteracies in the understandings of teachers who are charged with implementing educational reform. Paper presented at the International Conference on Technology in Education, Badajoz, Spain, November.

Zhao, Y. \& Rop, S. (2001). A critical review of the literature on electronic networks as reflective discourse communities for inservice teachers. Paper presented at the Annual Meeting of the American Education Research Association, New Orleans, April.

Glenice Watson and Sarah Prestridge

Griffith University, Nathan Qld 4111

G.A.Watson@griffith.edu.au 